\title{
TAVI specific sex consideration
}

\author{
Giulia Masiero', Valeria Paradies ${ }^{2}$, Anna Franzone ${ }^{3}$, Barbara Bellini ${ }^{4}$, Chiara De Biase ${ }^{5}$, Nicole Karam $^{6}$, \\ Francesca Sanguineti ${ }^{7}$, Hélène Eltchaninoff ${ }^{8}$, Chiara Fraccaro $^{1}$, Alaide Chieffo ${ }^{4}$ \\ 'Department of Cardiac, Thoracic, Vascular Science and Public Health, University of Padova, Padova 35128, Italy. \\ ${ }^{2}$ Department of Cardiology, Maasstad Hospital, Rotterdam 3079, Netherlands. \\ ${ }^{3}$ Department of Advanced Biomedical Sciences, Federico II University of Naples, Naples 80125, Italy. \\ ${ }^{4}$ Interventional Cardiology Unit, IRCCS San Raffaele Scientific Institute, Milan 20132, Italy; \\ ${ }^{5}$ Groupe CardioVasculaire Interventionnel, Clinique Pasteur, Toulouse 31076, France; \\ ${ }^{6}$ Cardiology Department, European Hospital Georges Pompidou, Paris 75015, France; \\ ${ }^{7}$ Institut Cardiovasculaire Paris Sud, Hôpital Privé Jacques CARTIER, Massy 91300, France; \\ ${ }^{8}$ Normandie University, UNIROUEN, U1096, CHU Rouen, Department of Cardiology, Rouen F-76000, France.
}

Correspondence to: Prof. Alaide Chieffo, Interventional Cardiology Unit, IRCCS San Raffaele Scientific Institute, 60, Via Olgettina, Milan 20132, Italy. E-mail: chieffo.alaide@hsr.it

How to cite this article: Masiero G, Paradies V, Franzone A, Bellini B, De Biase C, Karam N, Sanguineti F, Eltchaninoff H, Fraccaro C, Chieffo A. TAVI specific sex consideration. Mini-invasive Surg 2022;6:4. https://dx.doi.org/10.20517/2574-1225.2021.104

Received: 31 Aug 2021 First Decision: 26 Nov 2021 Revised: 5 Dec 2021 Accepted: 14 Dec 2021 Published: 6 Jan 2022

Academic Editor: Andrea Scotti Copy Editor: Xi-Jun Chen Production Editor: Xi-Jun Chen

\begin{abstract}
The impact of sex on baseline characteristics and morphological and clinical presentation of degenerative aortic stenosis has been widely demonstrated but poorly understood. Moreover, differently from valve surgery, where patients were predominantly male, both sexes have been well represented in percutaneous treatment of aortic stenosis (AS), and women appeared to derive greater benefit with transfemoral aortic valve implantation (TAVI) compared to surgical treatment. This review focuses on sex-specific differences in epidemiology, pathophysiology, diagnostic issues, treatment options, and clinical outcomes of degenerative AS. Moreover, we evaluate how sexbased TAVI management, from device selection to procedural tricks, may affect outcomes.
\end{abstract}

Keywords: Transcatheter aortic valve implantation, aortic stenosis, sex-specific differences, device selection, clinical management

\section{INTRODUCTION}

Although sex differences in coronary artery disease have been well appreciated, the impact of sex on valvular heart disease (VHD) has not been extensively discussed. Degenerative aortic stenosis (AS) currently 
represents one of the most common VHD conditions. Men and women demonstrate dissimilar baseline characteristics, morphological and clinical presentation, and outcomes ${ }^{[1]}$. Different from valve surgery, where patients were predominantly male, both sexes have been well represented in percutaneous treatment of $\mathrm{AS}^{[2]}$. Furthermore, women appeared to derive greater benefit compared to men with transfemoral aortic valve implantation (TAVI) compared to surgical treatment. This review focuses on sex-specific differences in the clinical management of degenerative AS, highlighting sex-specific technical considerations in the percutaneous treatment of the disease, taking into account the latest technological innovations. In particular, epidemiology, pathophysiology, diagnostic issues, treatment options, and clinical outcomes in the female AS population are reported. Moreover, we evaluate whether a sex-based TAVI management, from device selection to procedural tricks, might have an impact on clinical outcomes.

\section{SEX-SPECIFIC CONSIDERATION IN THE DIAGNOSIS AND TREATMENT OF AS Epidemiology of AS}

AS is the most prevalent valvular heart disease requiring intervention, surgery or transcatheter, in Europe and North America ${ }^{[3,4]}$. The prevalence of AS is $4 \%$ by echocardiography, with equal frequency in men and women and a mortality rate of over $50 \%$ at two years in symptomatic AS patients unless promptly treated. It occurs primarily as a consequence of degenerative calcific disease, so its prevalence is rising rapidly due to the aging population; it has been estimated that approximately 12\% (Europe) and 4\% (North America) of the elderly patients (> 75 years) have symptomatic severe $\mathrm{AS}^{[5]}$. Conversely, among the most frequent congenital anomalies, bicuspid aortic valve (BAV) is 3-4 times more prevalent in men as compared to women and is associated with earlier accelerated degeneration of the valve apparatus that tends to be more severe than in tricuspid aortic valve ${ }^{[4,5]}$. Although the evidence on the distribution of BAV phenotypes between sexes is not consistent, observational series showed higher prevalence of stenotic dysfunction in female patients compared to men more frequently affected by aortic regurgitation ${ }^{[4]}$. As rigorous evidence is still lacking in the percutaneous treatment of BAV, we focus our discussion on tricuspid aortic valve stenosis.

\section{Pathophysiology of degenerative AS}

It is now recognized that degenerative age-related valve mineralization is a dynamic process with lipid accumulation, chronic inflammation, and active valve leaflet calcification. It involves proinflammatory monocytes and activated endothelial cells that stimulate macrophage accumulation, proteolytic enzymes release, and the differentiation of myofibroblasts and smooth muscle cells into osteoblasts with resultant osteogenic activity. However, little is known about the role of sex in the etiology and progression of the disease.

To date, sex differences in the valves and the ventricular response to the pressure and volume overload due to valvular disease have not been completely elucidated [Figure 1]. A lower collagen I-II and matrix metalloproteinase 2 gene expression has been found in women $v s$. men in the interstitial cells of myocardial biopsy specimens performed at the time of surgery; adjunctively, on a molecular level, decreased extracellular fibrosis has been linked to the protective effect of estrogen in the female population. Therefore, women display different patterns of hypertrophy and remodeling, with a different extent of ventricular fibrosis and morphology of aortic valve disorder ${ }^{[2]}$. As a matter of fact, differently from males, women showed more frequent concentric left ventricular (LV) hypertrophy, smaller LV cavities, and greater relative wall thicknesses facing the increased afterload of worsening AS. However, women more often experience reversal of hypertrophy shortly after aortic valve replacement ${ }^{[6]}$. Moreover, studies comparing the extent of aortic valve calcification (AVC) measured by multidetector computed tomography (MDCT) in men and women with comparable degrees of AS revealed a lower AVC load, even after adjustment for body surface area and echocardiographic parameters ${ }^{[6]}$. Likewise, female sex was correlated to lower AVC progression 


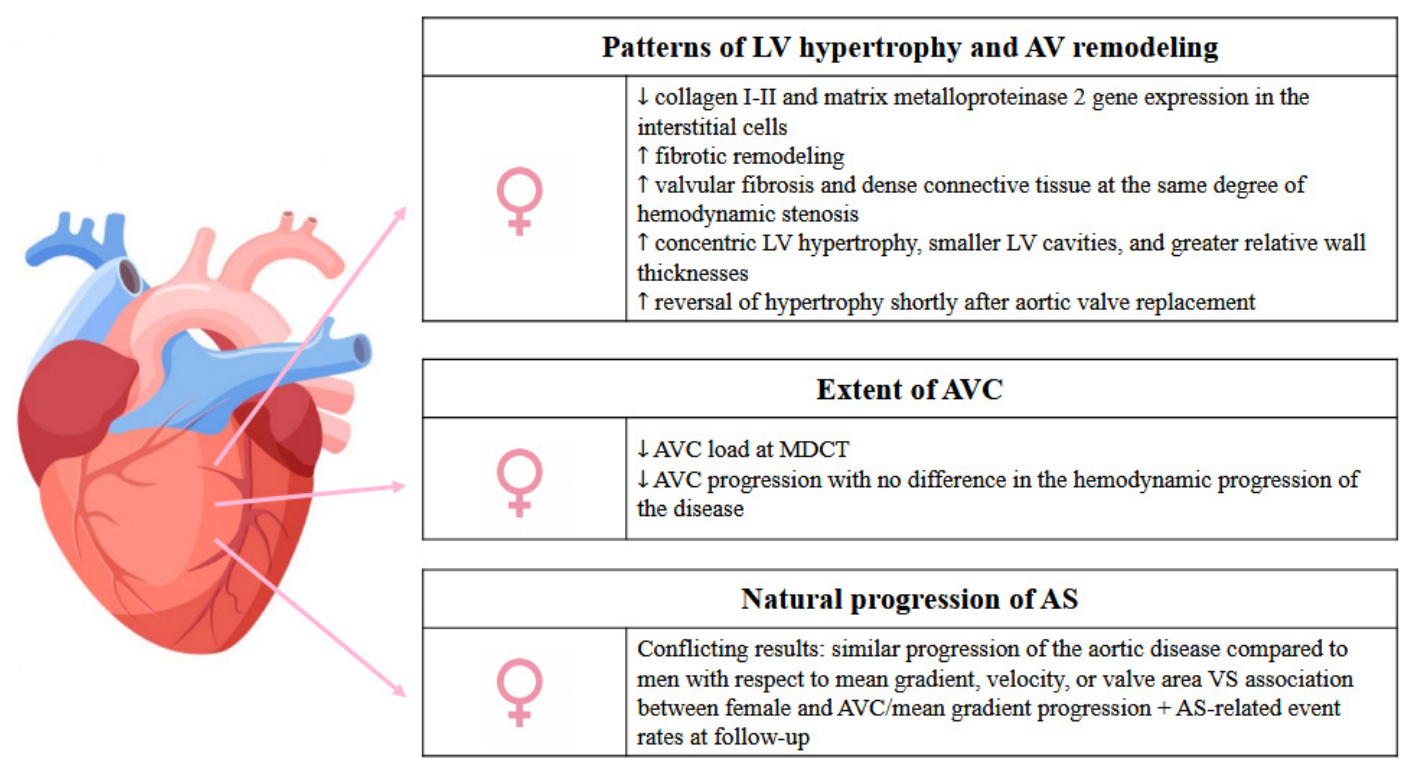

Figure 1. Summary image depicting the pathophysiological peculiar features of aortic stenosis in women. LV: Left ventricle; AS: aortic stenosis; AVC: aortic valve calcification; MDCT: multidetector computed tomography.

with no difference in the hemodynamic progression of the disease, probably due to a more pronounced fibrotic remodeling than men. Several studies showed the presence of higher levels of valvular fibrosis and dense connective tissue at the same degree of hemodynamic stenosis severity in women compared to men ${ }^{[7]}$.

There are conflicting data on the sex differences in the natural progression of $\mathrm{AS}^{[8]}$. Cramariuc et al..$^{[9]}$ reported similar progression of the aortic disease between men and women with respect to mean gradient, velocity, or valve area. Conversely, in the COFRASA-GENERAC study, female sex was an independent predictor of aortic valve calcification and mean gradient progression, showing a significant association with AS-related event rates at long-term follow-up ${ }^{[10]}$.

The effect of sex, as an important modulator of pathological processes associated with the development of AS, remains largely unexplored. Its comprehension remains extremely important, since it determines the development of different clinical phenotypes and following prognosis in men and women.

\section{Clinical presentation}

In patients presenting with AS, the sex discrepancy starts in the pathophysiology of the disease at valvular and ventricular levels and includes different calcification processes, fibrosis, and response to AS hemodynamic burden. Nevertheless, the clinical differences between men and women with AS and their link to management and outcomes remain poorly defined ${ }^{[7,11,12]}$. Increasing awareness of sex-related differences in clinical presentation and diagnosis translates into better characterization and decision-making strategies for this subset of patients with consequent improvement in clinical outcomes [Figure 2]. Women tend to present later; this often leads to a lower referral to treatment. Almost half of women with severe AS are asymptomatic, with a $1.0 \%-1.5 \%$ yearly rate of sudden cardiac death ${ }^{[13]}$. Women are diagnosed at later ages, with fewer comorbidities, and have more symptoms than men ${ }^{[12]}$. When symptoms appear, women are likely to have a higher rate of symptomatic heart-failure (New-York Heart Association class III-IV), with shortness of breath and dizziness/syncope as most frequent symptoms, and greater prevalence of chronic kidney disease ${ }^{[14]}$. The higher symptomatic burden in women may be explained by the higher relative wall thickness, a smaller LV cavity, and higher wall stress and filling pressures than men in the context of AS 


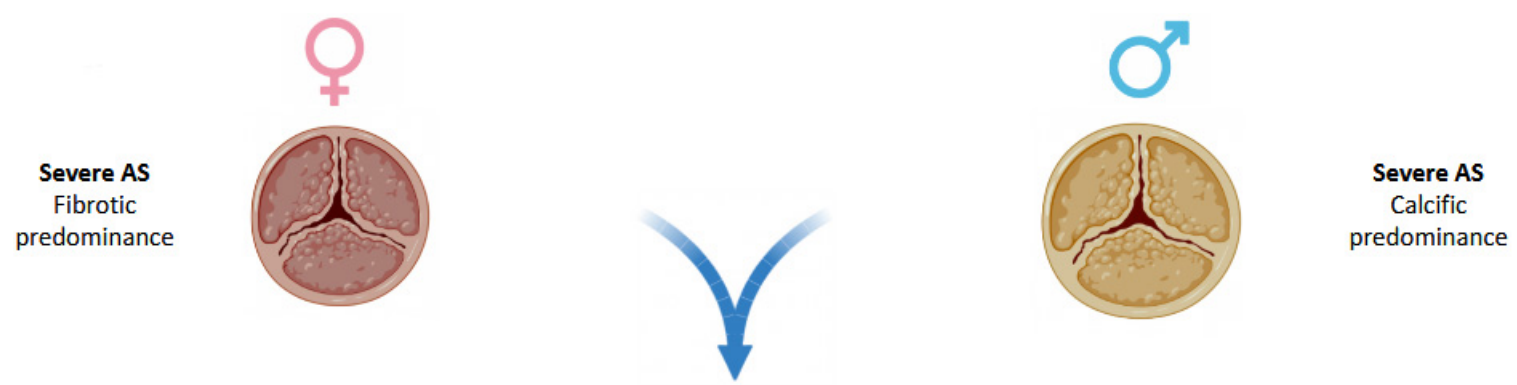

\begin{tabular}{|c|c|c|c|}
\hline $\begin{array}{c}\text { LV Hyperthrophy } \\
\text { Concentric remodelling } \\
\uparrow \text { paradoxic LF-LG AS }\end{array}$ & Echocardiography & $\begin{array}{l}\text { - Velocity/gradient } \\
\text { - LV hyperthrophy } \\
\text { - LVOT } \\
\text { - AVA }\end{array}$ & $\begin{array}{l}\text { LV Hyperthrophy } \\
\text { Eccentric remodelling }\end{array}$ \\
\hline $\begin{array}{c}\text { Aortic root } \\
\text { Smaller anulus } \\
\text { Lower coronay take off }\end{array}$ & MDCT & $\begin{array}{l}\text { - } \text { Aortic valve calcium } \\
\text { - } \text { Size and shape anulus } \\
\text { - } \text { Listance anulus-coronary ostia }\end{array}$ & $\begin{array}{c}\text { Aortic root } \\
\text { Larger anulus } \\
\text { Higher coronary take off }\end{array}$ \\
\hline $\begin{array}{c}\text { LV remodelling } \\
\downarrow \text { LV mass index } \\
\uparrow \text { myocardial fibrosis }\end{array}$ & CMR & $\begin{array}{l}\text { - } \text { Mass index } \\
\text { - } \text { LV hyperthrophy } \\
\text { - Pattern of fibrosis (LGE) } \\
\text { - } \text { LVOT }\end{array}$ & $\begin{array}{c}\text { LV remodelling } \\
\uparrow \text { LV mass index } \\
\downarrow \text { myocardial fibrosis }\end{array}$ \\
\hline
\end{tabular}

Figure 2. Illustrative representation of different aortic valve phenotypes in men and women according to diagnosis modalities. AS: Aortic stenosis; LV: left ventricle; LF-LG: low-flow low-gradient; OT: out-flow tract; AVA: aortic valve area; LGE: late gadolinium enhancement.

chronic pressure overload ${ }^{[15-17]}$. Per contra, men present with a higher prevalence of coronary artery disease, peripheral artery disease, and diabetes ${ }^{[8]}$. Considering that symptoms onset is a key factor in determining the timing of treatment, it is, therefore, relevant to take into account both clinical symptoms and imaging findings for decision-making strategy ${ }^{[4]}$.

\section{Diagnosis of AS}

Experts have questioned the lack of consistent sex-specific criteria in guidelines for the grading of disease severity. Echocardiographic criteria for the diagnosis of AS guarantee indexed values for body surface area (BSA) [aortic valve area (AVA) $<0.6 \mathrm{~cm}^{2} / \mathrm{m}^{2}$ ], an important distinction for women; however, the same does not apply for other hemodynamic parameters such as mean gradient or peak velocity ${ }^{[4,11]}$. However, transthoracic echocardiogram (TTE) does not allow for an accurate AVC and AVA quantification as the continuity equation may underestimate the LV outflow tract (LVOT) area and stroke volume, resulting in discrepancy between mean gradient and $\mathrm{AVA}^{[18,19]}$. Moreover, approximately $30 \%-55 \%$ of patients with severe AS have low flow-low gradient stenosis on echo. In 10\%-25\% of these patients, more commonly women, small, restrictive LV cavity, greater arterial stiffness, and higher ventriculoarterial impedance result in "paradoxical" underestimation of the severity of the AS [paradoxical low-flow/low-gradient (LFLG) AS] despite preserved LV systolic function ${ }^{[20]}$.

While echo remains the standard diagnostic test, cardiac magnetic resonance (cMR) and MDCT could provide complementary information on LV function and aortic valve calcification, respectively [Figure 2]. cMR allows identification of different patterns of hypertrophy and remodeling and extent of LV fibrosis at late gadolinium enhancement assessment ${ }^{[21]}$. MDCT could be used to provide more specific and detailed quantification of AVC severity and AS progression ${ }^{[22-24]}$. An integrated approach based on TTE and MDCT should be considered for reclassification of AVA, using the true MDCT measured LVOT area ${ }^{[25]}$. AVC load 
has been suggested as a surrogate marker of prognostic importance in AS patients as strongly associated with worse morbidity and mortality ${ }^{[26-30]}$. MDCT data of AS patients support sex-related differences in the levels of AVC load required to reach hemodynamically severe $\mathrm{AS}^{\left[{ }^{[8]}\right.}$. For the same degree of AS severity, women have a lower AVC load compared with men, also after adjustment for BSA, resulting in sex-specific calcium scores for the diagnosis of $A S^{[4,31,32]}$. They have a more fibrotic remodeling of the aortic valve with higher levels of valvular fibrosis and dense connective tissue at the same degree of hemodynamic stenosis severity, while men have a more calcific remodeling, irrespective of patients' age ${ }^{[33]}$. These discordant calcific/fibrotic patterns between men and women may be exacerbated by specific valve morphology. Women with stenotic bicuspid aortic valve have less calcification than men for the same hemodynamic severity of AS, as well as less calcification than women with stenosed tricuspid aortic valve $e^{[33]}$. Interestingly, despite lower AV calcium, women have more significant progression of AVC over three years of followup $^{[10]}$. This imbalance in clinical presentation and pathophysiological process should be brought to the attention of the cardiology community to ensure equivalent care for AS in men and women. Due to the different onset of symptoms and the different pathophysiological mechanisms, AS classification in women may further benefit from an integrated TTE and MDCT diagnostic approach in order to avoid late referral and adverse outcomes.

\section{Treatment choice}

In patients with severe symptomatic AS, valve replacement has a beneficial impact on survival, symptoms, and left ventricular function ${ }^{[34]}$. The choice between surgical aortic valve replacement (SAVR) and transcatheter intervention is based on patient's age and clinical and anatomic features ${ }^{[35]}$. International guidelines do not include specific recommendations for AS treatment according to sex. However, historically, women have been more often than men denied for SAVR ${ }^{[12,36]}$. Several reasons account for this unequal referral pattern: compared with men, women with AS feature older age, atypical symptoms, and more advanced cardiac disease despite preserved left ventricular ejection fraction ${ }^{[37]}$. In addition, men have higher prevalence of concomitant coronary artery disease requiring coronary artery bypass grafting, and physicians usually overestimate the operative risk of female patients by perceiving a greater risk related to their physical frailty ${ }^{[38]}$. This sex gap has partially narrowed with the widespread adoption of TAVI, as women represent more than $50 \%$ of the treated population ${ }^{[39]}$. The heart team plays a pivotal role in the selection of the optimal modality of intervention (surgical or transcatheter) based on several features and avoiding futility, especially for $\mathrm{TAVI}^{[4]}$. Female sex is a risk factor for perioperative mortality in both the EuroSCORE and the Society of Thoracic Surgeons Risk Score. However, sex is not listed among factors that could preferentially drive the choice between SAVR and TAVI. Historically, at the time of intervention, women present with advanced age at presentation and greater prevalence of higher frailty that potentially increases the risk of procedural complications and delays recovery after surgical intervention ${ }^{[38]}$. Despite the augmented incidence of adverse vascular events that are discussed below [Table 1], several further factors make female patients preferential candidates for TAVI than SAVR, including the lower prevalence of concomitant severe coronary artery disease and the lower occurrence of patient-prosthesis mismatch and paravalvular regurgitation despite small aortic annulus ${ }^{[4]}$. However, considering their longer life expectancy, assessing TAVI durability is of paramount importance even in higher risk cohorts. Long-term clinical results (> 10 years) on cardiovascular mortality, need of reintervention, and bioprosthetic valve failure (BVF) according to type treatment (surgical vs. percutaneous) and bioprosthesis (balloon vs. selfexpandable) are needed. In particular, the impact of sex on structural and non-structural mechanisms of valve deterioration still needs to be clarified. To date, only anecdotical observational experiences identified female sex, small BSA, and smaller size of THV as possible predictors of BVF ${ }^{[40]}$. 
Table 1. Main characteristics and results of studies comparing TAVI outcomes in women and men

\begin{tabular}{|c|c|c|c|c|c|c|c|}
\hline $\begin{array}{l}\text { Study/first author } \\
\text { (Ref.) }\end{array}$ & Design & $\begin{array}{l}\text { Overall } \\
\text { population }(n)\end{array}$ & $\begin{array}{l}\% \\
\text { women }\end{array}$ & $\begin{array}{l}\text { Balloon- } \\
\text { expanding valves } \\
(\%)\end{array}$ & $\begin{array}{l}\text { Self-expanding } \\
\text { valves (\%) }\end{array}$ & Follow-up & Main results \\
\hline FRANCE 2 Registry ${ }^{[85]}$ & $\begin{array}{l}\text { Prospective } \\
\text { observational }\end{array}$ & 3972 & 49.5 & 73.2 & 26.8 & 1 year & $\begin{array}{l}\text { Similar rate of mortality at } 1 \text { month ( } 9.5 \% \text { vs. } 9.2 \%) \text { and lower rate at 1-year than } \\
\text { men (19.3\% vs. } 23.7 \%)\end{array}$ \\
\hline Kodali et al. ${ }^{[86]}$ & $\begin{array}{l}\text { Analysis of } \\
\text { RCT }\end{array}$ & 2559 & 47.6 & 100 & 0 & 1 year & $\begin{array}{l}\text { Higher rate of vascular complications (17.3\% vs. } 10 \%) \text { and bleeding (10.5\% vs. } \\
7.7 \%) \text { in women than men; similar } 30 \text {-day mortality and lower 1-year mortality } \\
(19 \% \text { vs. } 25.9 \%)\end{array}$ \\
\hline Szerlip et al. ${ }^{[50]}$ & $\begin{array}{l}\text { Analysis of } \\
\text { RCT }\end{array}$ & 1661 & 39.5 & 100 & 0 & 1 year & $\begin{array}{l}\text { No difference in mortality at } 30 \text { days ( } 2 \% \text { vs. } 1.2 \% \text { ) and } 1-y e a r(9.3 \% \text { vs. } 10.2 \%) \text {. } \\
\text { Higher rates of major vascular complications in women (7.9\% vs. } 4.4 \%)\end{array}$ \\
\hline Sannino et al. ${ }^{[87]}$ & $\begin{array}{l}\text { Retrospective } \\
\text { observational }\end{array}$ & 910 & 46.5 & 57.7 & 42.3 & 1 year & $\begin{array}{l}\text { Higher rates of major vascular complications ( } 7.8 \% \text { vs. } 4.1 \% \text { ) and bleeding ( } 4 \% \text { vs. } \\
1.6 \% \text { ) in women. Lower rates of mortality at } 1 \text {-year ( } 7 \% \text { vs. } 12.7 \% \text { ) }\end{array}$ \\
\hline Doshi et al. ${ }^{[88]}$ & $\begin{array}{l}\text { Retrospective } \\
\text { observational }\end{array}$ & 41,050 & 47.7 & NA & NA & In-hospital & Higher rates of mortality ( $4.7 \%$ vs. $3.9 \%$ ) in women \\
\hline Stehli et al. ${ }^{[89]}$ & $\begin{array}{l}\text { Prospective } \\
\text { observational }\end{array}$ & 683 & 58 & 10.4 & 89.6 & 1 year & $\begin{array}{l}\text { Higher rates of major bleeding ( } 3.3 \% \text { vs. } 1 \% \text { ) and } 30 \text {-day mortality ( } 2.4 \% \text { vs. } \\
0.3 \% \text { ) in women. Similar rates of } 1 \text {-year mortality ( } 8.3 \% \text { vs. } 7.8 \%)\end{array}$ \\
\hline FRAILTY-AVR ${ }^{[38]}$ & $\begin{array}{l}\text { Prospective } \\
\text { observational }\end{array}$ & 759 & 44.8 & NA & NA & 1 year & $\begin{array}{l}\text { Higher rates of } 30 \text {-day mortality and major vascular complications in women. } \\
\text { Similar rates of 1-year mortality ( } 19 \% \text { vs. 17\%). }\end{array}$ \\
\hline TVT Registry ${ }^{[90]}$ & $\begin{array}{l}\text { Prospective } \\
\text { observational }\end{array}$ & 23,652 & 49.9 & 88.5 & 11.5 & 1 year & $\begin{array}{l}\text { Higher rates of vascular complications ( } 8.3 \% \text { vs. } 4.4 \% \text { ) and bleeding ( } 8 \% \text { vs. } \\
5.9 \% \text { ) in women. Lower rates of } 1 \text {-year mortality }(21.3 \% \text { vs. } 24.5 \%)\end{array}$ \\
\hline Forrest et al. ${ }^{[91]}$ & $\begin{array}{l}\text { Analysis of } \\
\text { RCT }\end{array}$ & 3687 & 46.3 & 0 & 100 & 1 year & $\begin{array}{l}\text { Higher rates of vascular complications ( } 9.7 \% \text { vs. } 4.9 \% \text { ) and bleeding ( } 29.7 \% \text { vs. } \\
21.7 \%) \text { in women. Similar rates of } 30 \text {-day }(5.9 \% \text { vs. } 5.8 \% \text { ) and } 1 \text {-year mortality } \\
(21.3 \% \text { vs. } 24.1 \%)\end{array}$ \\
\hline D'Ascenzo et al. ${ }^{[92]}$ & $\begin{array}{l}\text { Retrospective } \\
\text { observational }\end{array}$ & 377 & 57.2 & NA & NA & 2 years & $\begin{array}{l}\text { Higher rates of bleeding ( } 44 \% \text { vs. } 25 \% \text { ) and major vascular complications }(12.9 \% \\
\text { vs. } 9.8 \% \text { ). Similar rates of death at } 30 \text {-day at longest follow-up }\end{array}$ \\
\hline $\begin{array}{l}\text { Italian Multicenter } \\
\text { CoreValve registry }\end{array}$ & $\begin{array}{l}\text { Prospective } \\
\text { Observational }\end{array}$ & 659 & 55.8 & 0 & 100 & 13 months & No significant differences in peri-procedural event rates and mortality \\
\hline Humphries et al. ${ }^{[94]}$ & $\begin{array}{l}\text { Analysis of } \\
\text { RCT }\end{array}$ & 641 & 51.3 & 100 & 0 & 2 years & $\begin{array}{l}\text { Higher rates of bleeding ( } 21.6 \% \text { vs. } 15.8 \%) \text { and major vascular complications } \\
(12.4 \% \text { vs. } 5.4 \%) \text {. Lower rates of } 30 \text {-day }(6.5 \% \text { vs. } 11.2 \%) \text { and } 2 \text {-year mortality } \\
(27.9 \% \text { vs. } 38.3 \%)\end{array}$ \\
\hline Czarnecki et al. ${ }^{[95]}$ & $\begin{array}{l}\text { Retrospective } \\
\text { observational }\end{array}$ & 999 & 45.3 & 57.1 & 38 & 1 year & $\begin{array}{l}\text { Higher rates of bleeding ( } 14.5 \% \text { vs. } 12.6 \%) \text { and major vascular complications } \\
(18.7 \% \text { vs. } 16.7 \%) \text {. Similar rates of } 30 \text {-day and } 1 \text {-mortality }\end{array}$ \\
\hline Katz et al. ${ }^{[81]}$ & $\begin{array}{l}\text { Prospective } \\
\text { observational }\end{array}$ & 819 & 51 & 67.7 & 28.9 & 1 year & $\begin{array}{l}\text { Higher rates of bleeding ( } 11 \% \text { vs. } 3.8 \%) \text {, major vascular complications ( } 11.2 \% \text { vs. } \\
5.5 \%) \text {, and mortality at } 30 \text { days }(11.5 \% \text { vs. } 6.5 \%) \text {. Similar rates of } 1 \text {-year mortality } \\
(29.7 \% \text { vs. } 25.9 \%)\end{array}$ \\
\hline
\end{tabular}

TAVI: Transcatheter aortic valve implantation; RCT: randomized control trial. 


\section{Impact of sex on clinical outcomes}

Overall, the impact of sex on clinical outcomes after SAVR or TAVI is not clearly defined. Higher rates of mortality and peri-procedural complications have been reported among women than men receiving SAVR. In the Italian Observational Multicenter Registry (OBSERVANT), female sex was an independent predictor for risk-adjusted 30-day mortality [odds ratio $(\mathrm{OR})=2.34 ; P=0.043$ ] and transfusions $(\mathrm{OR}=1.47 ; P=$ $0.003)$ after $S A V R^{[41]}$. In a propensity-matched analysis from the Nationwide Inpatient Sample, in-hospital mortality was significantly higher in women compared with men following SAVR $(3.3 \%$ vs. $2.9 \%, P<0.001)$; they also had higher rates of vascular complications and blood transfusions ${ }^{[42]}$. Other studies did not find sex-related differences in short- and long-term mortality after SAVR or reported better outcomes in women $^{[43-46]}$. In the Women's INternational Transcatheter Aortic Valve Implantation (WIN TAVI) registry, the first study that specifically assessed the performance of TAVI in a population of solely women $(n=$ 1019), the primary Valve Academic Research Consortium (VARC)-2 early safety endpoint at 30 days (composite of mortality, stroke, major vascular complications, life-threatening bleeding, stage 2 or 3 acute kidney injury, coronary artery obstruction, or repeat procedure for valve-related dysfunction) was $14 \%$ with a low incidence of early mortality $(3.4 \%)$ and stroke $(1.3 \%)^{[47]}$. In addition, the VARC-2 efficacy endpoint (composite of mortality, stroke, myocardial infarction, hospitalization for valve-related symptoms or heart failure, or valve-related dysfunction) occurred in $10.9 \%$ and $16.5 \%$ of patients at 30 days and 1 year, respectively, and 1-year survival was better than in $\operatorname{men}^{[48]}$. The results of other observational studies and subgroups analysis of randomized trials that evaluated the impact of sex on clinical outcomes after TAVI are summarized in Table 1. Overall, in these studies, compared with men, women were older and with fewer comorbidities; they had higher rates of procedure-related vascular complications and bleeding, and they had comparable or even better survival at early and long term. Similarly, a patient-level data meta-analysis of 11,310 patients reported higher rates of major vascular complications, major bleeding events, and stroke in women (48.6\% of overall population) compared with men. However, female sex was found to be an independent predictor of late survival after TAVI [adjusted hazard ratio $=0.79 ; 95 \%$ confidence interval (CI): 0.73-0.86; $P=0.001]^{[39]}$. In a meta-analysis including 47,188 patients ( $49.4 \%$ women), female sex conveyed a lower risk of all-cause mortality at one year [risk ratio $(\mathrm{RR})=0.85 ; 95 \%$ CI: 0.79-0.91; $P<0.001$ ], despite a greater peri-procedural complications rate ${ }^{[49]}$. Several factors might explain the sex-related differences of clinical outcomes after TAVI and their peculiar time course. Advanced age, low body surface area, and small vessels make women at higher risk for bleeding and vascular complications in the early period after the procedure. Over a longer term, fewer comorbidities, lower occurrence of paravalvular regurgitation and patient-prosthesis mismatch, and a more favorable left ventricular remodeling could drive the survival advantage of women over men. In perspective, changing demographics of patients (younger and at lower risk), device, and procedural amelioration could mitigate the impact of sex on TAVI outcomes. In this regard, an analysis of the nonrandomized PARTNER II S3 trial showed equivalent mortality rates at one year for women and men ${ }^{[50]}$. Similarly, in a study of 298 patients receiving a new generation transcatheter heart valve [Sapien 3 (Edwards Lifesciences, Irvine, California) or Corevalve Evolut R or Evolut Pro (Medtronic, Minneapolis, Minnesota)], no significant differences were found in postprocedural outcomes including all-cause mortality between women and $\operatorname{men}^{[51]}$.

\section{TECHNICAL SEX-SPECIFIC CONSIDERATION IN TAVI}

\section{Access management}

Vascular complications still represent a relevant concern in TAVI procedures. In intermediate risk patients, major vascular complications (MVC) with third-generation transcatheter heart valves (THV) have an incidence ranging from $6 \%$ to $7.9 \%{ }^{[52]}$ and are associated with worse clinical outcomes with a prolonged hospital stay, an increased risk of wound infection, and a higher in-hospital mortality ${ }^{[53]}$. A recent subanalysis from the WIN TAVI registry has outlined that women experiencing MVC after TAVR are at significantly higher early risk of life-threatening or major bleeding and death and late risk of stroke, 
confirming the importance of careful access site management in female patients undergoing TAVI (In press).

\section{Assessment}

Access site should be thoroughly assessed by multi-slice computed tomography. CT scan can identify the presence of peripheral vascular disease, small size of ileo-femoral vessels, severe tortuosity, and calcifications, conditions that can increase the rate of vascular complication $s^{[54]}$. In particular, the extent and distribution of calcifications should be reported in order to plan the use of adjunctive treatments, such as intravascular lithotripsy of peripheral vessels, or the need for an alternative route ${ }^{[55]}$. CT scan is also of uttermost importance in the assessment of ileo-femoral vessels dimensions, being the sheath to femoral artery ratio (SFAR) a strong predictor of vascular complications. Female patients might have smaller vessel diameters resulting in an unfavorable SFAR, and this might explain the higher rate of vascular complications observed in this population ${ }^{[5]}$ [Figure 3]. If transfemoral access is not feasible, alternative peripheral vascular approaches such as transubclavian/transaxillary/transcarotid/transapical/transaortic/transcaval (in order of importance) may be considered if the risk is deemed high and the patient is inoperable.

\section{Puncture}

Femoral puncture can be obtained using fluoroscopy guidance with contralateral angiography (FCA) or with the use of two-dimensional ultrasound (2D-US). A recent study reported no difference in the risk of vascular and bleeding complications according to the femoral puncture technique used [FCA $v s .2 \mathrm{D}-\mathrm{US}$ : 6.7\% (95\%CI: $4.9 \%-8.9 \%$ ) vs. $6.8 \%$ (95\%CI: $4.8 \%-9.3 \%$ ); $P=0.63 ; 6.1 \%$ (95\%CI: $4.4 \%-8.2 \%$ ) vs. $6.4 \%$ (95\%CI: $4.8 \%-9.3 \%) ; P=0.70$ respectively $]^{[57]}$. However, it can be speculated that in specific subsets of patients (small vessels and severe calcification), 2D-US guidance might improve patients' outcomes.

\section{Closure}

Different vascular closure devices (VCD) have been used in order to reduce vascular complications. In a post hoc analysis from the BRAVO-3 (Bivalirudin $v$ s. heparin anti-coagulation in transcatheter aortic valve replacement) trial, in comparison to the Prostar device (Abbott Vascular, Santa Clara), the use of two Proglide devices (Abbott Vascular, Santa Clara) was associated with a lower rate of major or minor vascular complications and lower rates of acute kidney injury in patients undergoing transfemoral TAVI ${ }^{[58]}$. In line with these results, the recent sub-analysis from the WIN TAVI Registry identified the use of Proglide as an independent predictor of reduction of MVC [hazard ratio (HR) $=0.49$; 95\%CI: 0.28-0.84; $P=0.010$ ] (In press). Moreover, to increase the safety of the percutaneous closure of the primary TAVI access, the radial modified crossover technique for controlled angiography and balloon inflation of the therapeutic access site might be used ${ }^{[59]}$.

In conclusion, women undergoing TAVI experience more vascular complications than their male counterparts. MVC is related to worse clinical outcomes. A careful CT scan access assessment along with the use of US in selected cases, a minimalistic approach with a "diagnostic" radial access, and the adequate use of VCD for percutaneous closure of the primary access might reduce the incidence of MVC and improve patient outcomes.

\section{Device selection}

In recent years, the continuous technological evolution guided by a growing clinical experience has led to the development of new iterations of preexisting THV platforms and newly designed THV systems, with subsequent improvement in valve hemodynamic and reduction in procedural complications. Moreover, with the advent of multimodal three-dimensional imaging (in particular, CT scan) as the gold standard in 


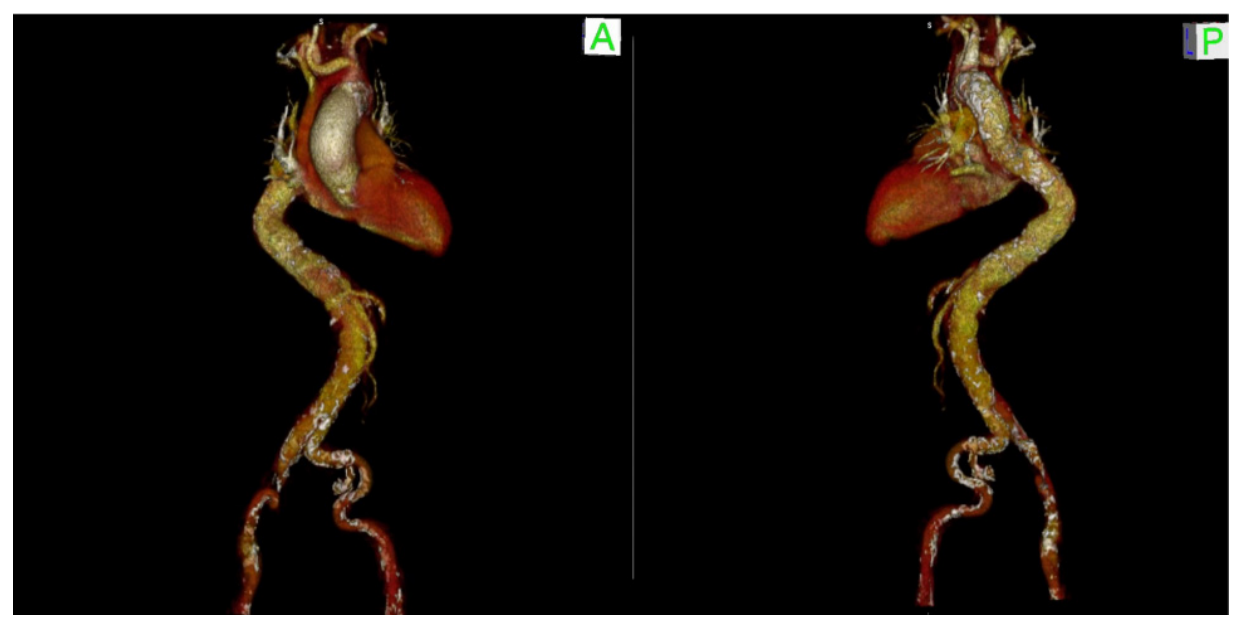

Figure 3. Multidetector computed tomography scan 3D reconstruction showing severe tortuosity of thoracic descending aorta and iliac arteries.

the screening of TAVI candidates, a lot of anatomical-clinical correlations have become more and more evident, affording the opportunity to select the most appropriate device for each individual anatomy (and patient), according to a tailored, patient-centered modern concept of medicine ${ }^{[00-64]}$. The possible different choice of THV between a male and a female patient affected by AS is related to different anatomical characteristics and peculiar pathophysiological features of AS according to sex, as previously detailed. Women, compared with men, present with particular recurring anatomical characteristics, on which we try to focus on guiding the choice of the prosthesis in particular circumstances. Recurrent anatomical characteristics among women affected by AS are the presence of a small body surface area, small anatomic root (including small annulus, sinus of Valsalva, and sino-tubular junction), low coronary take off, and small ileo-femoral vessels. Moreover, accumulating evidence suggests that, in patients with degenerative AS, sex can determine important differences in the pathophysiological processes of development and progression of AS, leading to a higher prevalence of fibrosis than calcification in stenotic aortic valves of female patients in comparison to men. Similar differences are also present at the ventricular level, with more pronounced cardiac hypertrophy and fibrosis in women than men, which translates into concentric hypertrophic LV remodeling with small and hypertrophic LV cavity, more frequent paradoxical LFLG AS phenotypes, and final development of heart failure with preserved ejection fraction ${ }^{[8]}$.

Considering all these anatomical features, it is possible to speculate which THVs might have potential advantages in women.

Aortic root anatomy, risk of prosthesis patient mismatch, and coronary occlusion

First, on the basis of the manufacturer's recommendations, the THVs that cover the smallest annular dimension $(<21 \mathrm{~mm}$ ) are CoreValve iterations (Evolut R, Pro and Pro+, Medtronic, Minneapolis, Minnesota), Edwards Sapien 3/Ultra (Edwards LifeSciences, Irvine, CA, USA), Myval (Meril Life Sciences Pvt. Ltd., Vapi, Gujarat, India), Portico/Navitor Valve (Abbott Structural Heart, St Paul, MN, USA), and Allegra valve (New Valve Technology, Hechingen, Germany). Differently, Acurate Neo and Neo 2 valve (Boston Scientific, Marlborough, MA, USA) are not indicated, according to the sizing chart, for mean annulus diameter $<21 \mathrm{~mm}^{[63]}$. Moreover, small annuli bear the risk of high residual post-procedural gradients and patient-prosthesis mismatch (PPM). Thus, as a general principle, the use of THVs with supraannular leaflet attachment, such as CoreValve iterations, may be advantageous in such anatomies, allowing to achieve the best hemodynamic performances ${ }^{[6]}$. In the CHOICE-Extend registry which included new 
generation devices, Sapien 3 THVs yielded smaller effective orifice area (EOA) and a higher residual gradient than Evolut R THVs, and multivariate regression analysis revealed that the use of the Evolut R was significantly associated with a lower risk for PPM, especially in patients with small annuli $<23 \mathrm{~mm}^{[65]}$. In addition, in the Ocean TAVI registry, Evolut R seems to be superior to Sapien 3 in hemodynamic performance for patients with a small annulus $(<23 \mathrm{~mm}$ ) up to one year after TAVI (mean prosthesis gradient $9.0 \mathrm{mmHg} v s .12 .0 \mathrm{mmHg} ; P<0.001$ and index EOA $1.20 \mathrm{~cm}^{2} / \mathrm{m}^{2} v s .1 .08 \mathrm{~cm}^{2} / \mathrm{m}^{2}, P<0.001$ ), with a lower incidence of moderate PPM (6.9\% vs. $28.4 \%$; $P=0.015)$ in the extremely small annulus-matched cohort $(<21 \mathrm{~mm})$. Nevertheless, severe prosthesis-patient mismatch and all-cause mortality at one year were similar between the two groups ${ }^{[6]]}$. The supra-annular designed self-expandable ACURATE neo valve also resulted in lower transvalvular gradients compared with the SAPIEN 3 Valve (mean gradient $7 \mathrm{mmHg}$ vs. $11 \mathrm{mmHg}$; $<0.0001$ ), as shown in the SCOPE I randomized trial and in another multicenter propensity-matched analysis reporting less PPM with Acurate Neo compared to SAPIEN 3 in patients with an aortic annulus area $<400 \mathrm{~mm}^{2[67,68]}$.

The particularly favorable hemodynamic performance granted by supra-annular devices could theoretically be an advantage not only in small anatomies but also in the case of paradoxical LFLG AS, when it is of utmost importance to implant a device with the best hemodynamic performance possible. Paradoxical LFLG AS is described in about $10 \%$ of TAVI patients in large real-world registries, and it is more frequently encountered in female patients. There is evidence supporting a similar mid-term prognosis after TAVI procedure in paradoxical LFLG patients than in high gradient AS patients, despite higher perioperative mortality; however, the impact of device selection in this condition is hypothesized and still has to be demonstrated ${ }^{[60]}$.

Regarding the risk of acute coronary occlusion after TAVI, this rare complication is described more frequently in women, in patients receiving a balloon-expandable valve, and in those with a previous surgical bioprosthesis; lower-lying coronary ostium and shallow sinus of Valsalva were associated anatomic factors $^{[70]}$. In cases where the risk of coronary occlusion is considered significant, the availability of repositionable/retrievable TAVI systems should be considered. However, all these potential advantages of supra-annular self-expandable devices must always be counterbalanced by the lower rate of selective coronary cannulation described with these $\mathrm{THVs}^{[71]}$. Reasons for impaired coronary selective cannulation with supra-annular devices are the taller-frame design, higher leaflets' position, and asymmetric skirt, which might hinder coronary access if a commissural post is placed in front of a coronary ostium. Even if this issue could be mitigated by commissural alignment technique during valve deployment, nevertheless, in patients with concomitant coronary artery disease, small sino-tubular junction, and in younger patients, when the need for future TAVI-in-TAVI is likely expected, a short frame balloon-expandable device (Sapien iterations or Myval) should be advised ${ }^{[72]}$.

\section{Small ilio-femoral vessels and risk of vascular complications}

Finally, frailty and small body surface area oriented the choice towards lower profile THVs family, more adapted to the small iliofemoral diameters. The CoreValve Evolut $\mathrm{R}$ and now also the new generation Evolut Pro+ can be implanted using the InLine ${ }^{\mathrm{ma}}$ (Medtronic) sheath with 14 Fr outer diameter equivalent (minimum vessel diameter requirements $5.0 \mathrm{~mm}$ for sizes 23,26 , and $29 \mathrm{~mm}$, in the absence of circumferential calcification). In addition, the last generation low-profile delivery system FlexNav (Abbott), designed for Portico and Navitor valve (Abbott), provides the same low insertion profile (access down to $5.0 \mathrm{~mm}$ vessels). Specifically, the FlexNav DS features a hydrophilic-coated, integrated sheath to minimize vessel trauma at the access site. This technological improvement allowed reducing the insertion force and increasing deliverability respect to Evolut Pro valve with Enveo Pro. The rate of access site-related major 
vascular complications obtained with FlexNav DS is below 5\% in a cohort of high-risk/extreme-risk subjects treated with this device: this compares very well to the low-risk cohort of patients enrolled in the Evolut low-risk trial and in Partner 3 trial (rate of major vascular complications of 3.8\% and 2.0\%, respectively) ${ }^{[73]}$. The Sapien 3/Ultra THVs can be implanted using a dedicated 14 or 16 Fr expandable eSheath technology, which temporarily expands as the device passes through the iliofemoral vessels (minimum diameter $5.5 \mathrm{~mm}$ for size 20, 23, and $26 \mathrm{~mm}$ ) and then recoils to its smaller caliber. All details about annulus covering range, delivery sheath size, and minimum vessels diameter requirements for different THVs are provided in Figure $4^{[63,74]}$.

\section{Procedural tricks}

While performing a TAVI in women, several precautions related to the anatomical specificities discussed above should be kept in might [Figure 5].

First, the risk of major complications is higher and is associated with worse prognosis ${ }^{[5,52]}$. The small vascular diameter and the calcifications are two of the major reasons for these complications. Efforts should be made to optimize vascular assessment on CT scan before the procedure, and an alternative route should be considered if the risk is deemed high. When a femoral access has been selected, while there was no proven advantage of $2 \mathrm{D}$-US over FCA for vascular puncture guidance ${ }^{[57]}$, combining both techniques can be considered in some cases to increase procedural safety, preferably using radial modified crossover technique. Prostar should be avoided, probably replaced by the use of two Proglide devices, as discussed above, while awaiting more data regarding the potential advantage of other devices such as Manta in women. In the case of heavy calcifications, intravascular lithotripsy should be considered. Choosing a device with low-profile delivery system, as discussed above, should be privileged. Finally, the risk of venous vascular complications should not be neglected, and over-the-wire rapid pacing should be preferred to the insertion of a temporary pacing probe when possible.

Another important aspect is related to aortic valve and root size and configuration. The combination of small body surface area, small anatomic root, and a low coronary take-off, which are all more frequent in women, should influence the choice of valve type as well as the procedure itself. As discussed above, supraannular self-expanding valves can help reduce the risk of transvalvular gradient, and commissural alignment should be targeted to allow future coronary arteries catheterization.

Moreover, taking into account the longer life expectancy of women, it is particularly advisable to customize the implantation strategy of supra-annular THV (when selected) in order to foresee future valve reintervention. Accordingly, the implantation level of the prosthesis should ensue from the trade-off of the pace-maker risk at the first procedure and the sinus sequestration at the future TAVI-in-TAVI intervention. In patients with a high risk of coronary obstruction due to coronary take-off, coronary protection should be realized using the chimney technique, with the catheterization of the jeopardized coronary and positioning a wire and a stent distally, before inserting the valve. The use of transcatheter electrosurgery for aortic leaflet laceration to prevent iatrogenic coronary artery obstruction (BASILICA) is also a promising alternative $\mathrm{e}^{[57]}$.

Finally, a frequent encounter among women is the presence of a small left ventricular cavity which might increase the risk of perforation. Choosing the appropriate wire and, more importantly, the appropriate distal end shape, is paramount to allow safe anchoring into the ventricle. For operators who are used to shaping their own wire tip, a smaller loop should be applied to the distal end. Otherwise, choosing dedicated pre-shaped stiff guidewire with a small curve is a tempting alternative, allowing a safer procedure. For example, the Amplatz Extra-Stiff APEX wire has a double curve design composed of a larger curve with the 


\section{A Balloon-expandable devices}

\begin{tabular}{|c|c|c|c|c|c|c|}
\hline & $\begin{array}{l}\text { DEVICE } \\
\text { TYPE }\end{array}$ & SIZE & $\begin{array}{l}\text { ANNULUS } \\
\text { DIAMETER }\end{array}$ & $\begin{array}{l}\text { ANNULUS } \\
\text { AREA }\end{array}$ & SHEATH SIZE & MVD REQUIREMENTS* \\
\hline \multirow{4}{*}{$\Leftrightarrow \rightarrow$} & \multirow{4}{*}{$\begin{array}{c}\text { SAPIEN } 3 \text { / } \\
\text { ULTRA }\end{array}$} & 20 & $18.6-21 \mathrm{~mm}$ & $273-345 \mathrm{~mm}$ & \multirow{3}{*}{14 Fr eSheath Introducer } & \multirow{3}{*}{$5.5 \mathrm{~mm}$} \\
\hline & & 23 & $20.7-23.4 \mathrm{~mm}$ & $338-430 \mathrm{~mm}$ & & \\
\hline & & 26 & $23.4-26-4 \mathrm{~mm}$ & $430-546 \mathrm{~mm}$ & & \\
\hline & & 29 & $26.2-29.5 \mathrm{~mm}$ & $540-680 \mathrm{~mm}$ & 16 Fr eSheath Introducer & $6.0 \mathrm{~mm}$ \\
\hline \multirow{9}{*}{ Mosing } & \multirow{9}{*}{ MYVAL } & 20 & $16-19 \mathrm{~mm}$ & $270-330 \mathrm{mmq}$ & \multirow{4}{*}{ 14Fr Python - Introducer Sheath } & \multirow{4}{*}{$5.5 \mathrm{~mm}$} \\
\hline & & 21.5 & $17.5-20.5 \mathrm{~mm}$ & $314-380 \mathrm{mmq}$ & & \\
\hline & & 23 & $18-22 \mathrm{~mm}$ & $360-440 \mathrm{mmq}$ & & \\
\hline & & 24.5 & $19.5-23.5 \mathrm{~mm}$ & $410-500 \mathrm{mmq}$ & & \\
\hline & & 26 & $21-25 \mathrm{~mm}$ & $460-560 \mathrm{mmq}$ & \multirow{3}{*}{ 14Fr Python - Introducer Sheath } & \multirow{3}{*}{$6.0 \mathrm{~mm}$} \\
\hline & & 27.5 & $22.5-26.5 \mathrm{~mm}$ & $510-630 \mathrm{mmq}$ & & \\
\hline & & 29 & $24-28 \mathrm{~mm}$ & $570-700 \mathrm{mmq}$ & & \\
\hline & & 30.5 & $25.5-29.5 \mathrm{~mm}$ & $630-770 \mathrm{mmq}$ & \multirow{2}{*}{ 14Fr Python - Introducer Sheath } & \multirow{2}{*}{$6.5 \mathrm{~mm}$} \\
\hline & & 32 & $27-31 \mathrm{~mm}$ & $700-840 \mathrm{mmq}$ & & \\
\hline
\end{tabular}

\section{B Self-expandable devices}

\begin{tabular}{|c|c|c|c|c|c|c|}
\hline & $\begin{array}{l}\text { DEVICE } \\
\text { TYPE }\end{array}$ & SIZE & $\begin{array}{l}\text { ANNULUS } \\
\text { DIAMETER }\end{array}$ & $\begin{array}{l}\text { ANNULUS } \\
\text { PERIMETER }\end{array}$ & SHEATH SIZE & MVD REQUIREMENTS* \\
\hline & \multirow{4}{*}{$\begin{array}{l}\text { COREVALVE } \\
\text { EVOLUT R / } \\
\text { PRO / PRO+ }\end{array}$} & 23 & $18-20 \mathrm{~mm}$ & $56.6-62.8 \mathrm{~mm}$ & \multirow{3}{*}{$\begin{array}{c}14 \mathrm{Fr} \text { equivalent (Evolut R/PRO+) } \\
16 \mathrm{Fr} \text { equivalent (Evolut PRO) }\end{array}$} & \multirow{3}{*}{$\begin{array}{c}5.0 \mathrm{~mm} \text { (Evolut R/PRO+) } \\
5.5 \mathrm{~mm} \text { (Evolut PRO) }\end{array}$} \\
\hline & & 26 & $20-23 \mathrm{~mm}$ & $62.8-72.3 \mathrm{~mm}$ & & \\
\hline & & 29 & $23-26 \mathrm{~mm}$ & 72.3-81.7 mm & & \\
\hline & & 34 & $26-30 \mathrm{~mm}$ & $81.7-94.2 \mathrm{~mm}$ & $\begin{array}{c}16 \text { Fr equivalent (Evolut } \mathrm{R} \text { ) } \\
18 \mathrm{Fr} \text { equivalent (Evolut } \mathrm{PRO}+\text { ) }\end{array}$ & $\begin{array}{c}5.5 \mathrm{~mm} \text { (Evolut R) } \\
6.0 \mathrm{~mm} \text { (Evolut PRO+) }\end{array}$ \\
\hline & \multirow{3}{*}{$\begin{array}{c}\text { ACURATE } \\
\text { NEO / NEO } \\
\mathbf{2}\end{array}$} & $\mathrm{S}$ & $21-23 \mathrm{~mm}$ & $66-72 \mathrm{~mm}$ & \multirow{3}{*}{$14 \mathrm{Fr}$ iSLEEVE Introducer } & \multirow{3}{*}{$5.5 \mathrm{~mm}$} \\
\hline & & $\mathrm{M}$ & $23-25 \mathrm{~mm}$ & $72-79 \mathrm{~mm}$ & & \\
\hline & & $\mathrm{L}$ & $25-27 \mathrm{~mm}$ & $79-85 \mathrm{~mm}$ & & \\
\hline & \multirow{4}{*}{$\begin{array}{l}\text { PORTICO / } \\
\text { NAVITOR }\end{array}$} & 23 & $19-21 \mathrm{~mm}$ & $60-66 \mathrm{~mm}$ & \multirow{3}{*}{$14 \mathrm{Fr}$ equivalent } & \multirow{3}{*}{$5.0 \mathrm{~mm}$} \\
\hline & & 25 & $21-23 \mathrm{~mm}$ & $66-73 \mathrm{~mm}$ & & \\
\hline & & 27 & $23-25 \mathrm{~mm}$ & $72-79 \mathrm{~mm}$ & & \\
\hline & & 29 & $25-27 \mathrm{~mm}$ & $79-85 \mathrm{~mm}$ & 15 Fr equivalent & $5.5 \mathrm{~mm}$ \\
\hline if & \multirow{3}{*}{ ALLEGRA } & 23 & $19-22 \mathrm{~mm}$ & $59.7-69.1 \mathrm{~mm}$ & \multirow{3}{*}{15 Fr equivalent } & \multirow{3}{*}{$5.5 \mathrm{~mm}$} \\
\hline & & 27 & $22-25 \mathrm{~mm}$ & $69.1-78.5 \mathrm{~mm}$ & & \\
\hline & & 31 & $25-28 \mathrm{~mm}$ & $78.5-88.0 \mathrm{~mm}$ & & \\
\hline
\end{tabular}

Figure 4. Annulus covering range and vessels diameter requirements of different balloon expandable $(A)$ and self-expandable (B) THVs. ${ }^{*}$ MVD: Minimum vessel diameter requirements (MSCT derived), excluding circumferential $\mathrm{Ca}^{2+} ; \mathrm{THV}_{\mathrm{s}}$ : transcatheter heart valves; MSCT: multi-slice computed tomography.

distal tip of the wire forming a $2 \mathrm{~mm} \mathrm{~J}$ bend; it can easily maneuver in smaller ventricles, while the Safari2 TM wire is available in three different loop sizes, offering the possibility to select the curve size according to the size of the ventricle.

\section{Pharmacological management}

The choice of the optimal antithrombotic regimen peri- and post-TAVI is of utmost importance [Figure 6]. Thromboembolic and bleeding complications are frequent and can be potentially life-threatening ${ }^{[51,75,76]}$. 


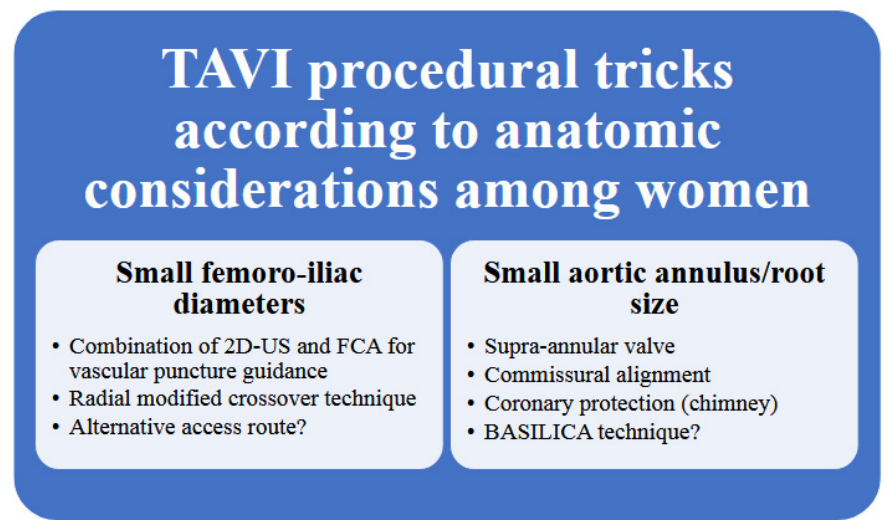

Figure 5. TAVI procedural tricks according to anatomic considerations among women. FCA: Fluoroscopy guidance with contralateral angiography; 2D-US: two-dimensional ultrasound.

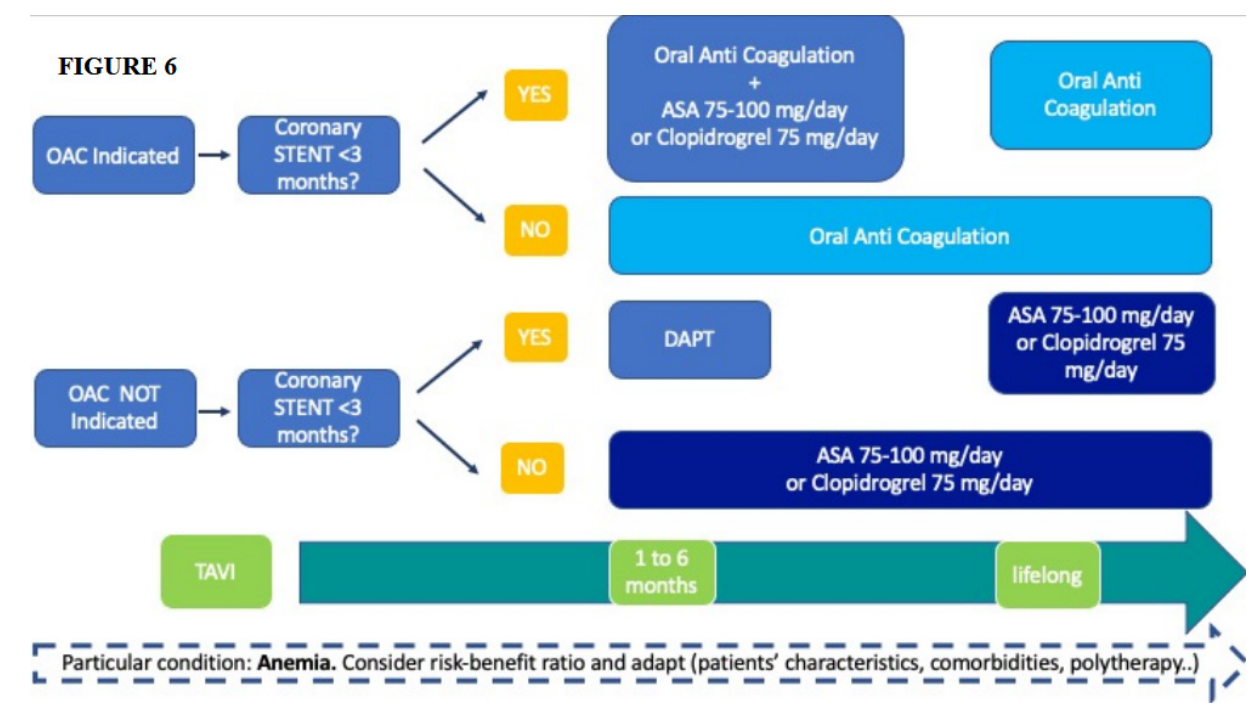

Figure 6. Optimal antithrombotic regimen post-TAVI procedure. OAC: Oral anticoagulation; DAPT: dual antiplatelet therapy; ASA: acid acetilsalicilic.

The 2021 ESC/EACTS guidelines recommend life-long single antiplatelet therapy or oral anticoagulation $(\mathrm{OAC})$ in the case of patients who have other indications for OAC, while dual antiplatelet therapy should be administered only in the case of recent percutaneous coronary intervention ${ }^{[4]}$. The $2020 \mathrm{ACC} / \mathrm{AHA}$ guidelines recommend life-long low-dose aspirin post-TAVI (IIa), while aspirin plus clopidogrel or vitamin K anticoagulation (VKA) for 3-6 months may be considered in patients with low bleeding risk (IIb) ${ }^{[35]}$. Cohort A of POPular TAVI randomized trial has recently shown a benefit in terms of incidence of bleeding in patients without an $\mathrm{OAC}$ indication receiving aspirin alone $v s$. patients receiving aspirin plus clopidogrel [risk ratio $(\mathrm{RR})=0.57 ; 95 \% \mathrm{CI}: 0.42-0.77 ; P=0.001$ ], while the composite of cardiovascular death, stroke, or myocardial infarction for aspirin alone was non-inferior to aspirin plus clopidogrel $(9.7 \%$ and $9.9 \%, P=$ 0.004 for non-inferiority $)^{[77]}$. Among patients undergoing TAVI, $40 \%$ have an indication for OAC. This subset of patients has been investigated in Cohort B of POPular TAVI trial, where a (novel) oral anticoagulation (N)OAC alone strategy has been compared to a (N)OAC plus clopidogrel for three months. Bleeding was significantly lower with (N)OAC alone vs. (N)OAC plus clopidogrel $(21.7 \%$ vs. $34.6 \%$; $\mathrm{RR}=$ 0.63; 95\%CI: $0.43-0.90 ; P=0.01)$, while the composite of cardiovascular death, stroke, or myocardial 
infarction was non-inferior $(13.4 \% \text { and } 17.3 \% \text {, respectively; } 95 \% \mathrm{CI} \text { for non-inferiority, }-11.9 \text { to } 4.0)^{[78]}$. The results of the recent GALILEO do not support rivaroxaban plus aspirin after TAVI in patients without an OAC indication, while evidence supporting (N)OAC over VKA after TAVI in AF patients is currently lacking ${ }^{[79]}$. The results of these recent trials have been translated in the consensus document from the ESC Working Group on Thrombosis and the European Association of Percutaneous Cardiovascular Interventions, in collaboration with the ESC Council on Valvular Heart Disease on "management of antithrombotic therapy in patients undergoing transcatheter aortic valve implantation"[80].

However, no specific recommendations have been indicated for women undergoing TAVI procedures. In both Cohort A and Cohort B from POPular TAVI, almost half of the enrolled patients were women, with no differences among the compared groups. However, no sub-analysis has been carried out to investigate differences in outcomes by sex. Differences between males and females in short- and long-term clinical outcomes of TAVI might exist ${ }^{[39]}$. However, evidence based on randomized studies is lacking, and several small studies yielded non-conclusive results ${ }^{[48-50,81]}$. Data from observational studies suggest sex disparities in antiplatelet and antithrombotic management after TAVI; specifically, women were more likely to be prescribed clopidogrel and less likely to be prescribed warfarin due to lower rates of atrial fibrillation in women. Even though disparities in clinical presentation and procedural management were observed, no significant difference in clinical outcomes was noted ${ }^{[51]}$. A large meta-analysis of registry data published in 2015 demonstrated women had higher rates than men of major bleeding, vascular complications, and stroke following TAVI; however, female sex was independently associated with improved survival at median follow-up of one year ${ }^{[39]}$. A recent meta-analysis of 47,188 patients ( $49.4 \%$ women) including low-risk patients investigated TAVI outcomes by sex. At 30 days, women had more bleeding $(P<0.001)$, vascular complications $(P<0.001)$, and stroke/transient ischemic attack $(P=0.02)$, while no differences emerged in all-cause $(P=0.19)$ or cardiovascular death $(P=0.91)$ as compared to $\operatorname{men}^{[49]}$.

The role of sex in determining the pharmacokinetic and pharmacodynamic responses to antithrombotic medications has already been established ${ }^{[82]}$. Importantly, signals of an increased risk of bleeding in women have been identified, and this aspect deserves clinical attention.

Moreover, female sex is an independent predictor of anemia in patients with severe aortic stenosis ${ }^{[33]}$. The WIN-TAVI registry showed that not only is anemia a common finding in elderly females, but it is also strongly related to the long-term prognosis. Nevertheless, patients with severe anemia were more likely to be discharged on oral anticoagulants than those with mild-to-moderate or no anemia, partially explained by the higher prevalence of peripheral artery disease ${ }^{[8]}$. Therefore, in the case of OAC therapy, particular attention has to be paid to hemoglobin values, and an accurate revaluation of the thrombotic and bleeding risks might be suggested during follow up. As bleeding and vascular complications are essential issues for women undergoing TAVI, antithrombotic and anticoagulant therapy should be established, paying particular attention to patients' characteristics, presence of comorbidities, and polytherapy that may predispose to bleeding and thrombosis. Additionally, a greater awareness of sex-related issues in antithrombotic and anticoagulant therapy should be promoted among physicians, and further evidence from large clinical trials looking at the safety and efficacy balance of different antithrombotic strategies in women is warranted to better inform the therapeutic decision making in daily clinical practice.

\section{CONCLUSIONS}

\section{Unsolved issues and future directions}

Different pathophysiology, baseline and morphological characteristics, clinical presentation, and outcomes have been observed in women with AS undergoing TAVI. However, differently from ischemic heart disease 
trials, female patients represent in general half of the patients treated with TAVI in clinical studies.

Nevertheless, the impact of sex in female patients with AS has not been still well evaluated and taken into appropriate consideration. Clinical studies designed specifically on the peculiarities of female patients with AS treated with TAVI are then warranted in order to tailor the treatment on those peculiarities.

Currently, the "Randomized researcH in womEn All Comers With Aortic Stenosis" trial is ongoing and randomizing female patients with AS to receive either TAVI or aortic valve replacement indication for AVR. The study assumes that from available scientific data in female patients, TAVI is not inferior to AVR in the study primary end points.

\section{DECLARATIONS}

\section{Authors' contributions}

Participated in drafting, revising and approval of the manuscript submitted: Masiero G, Paradies V, Franzone A, Bellini B, De Biase C, Karam N, Sanguineti F, Eltchaninoff H, Fraccaro C, Chieffo A

\section{Availability of data and materials}

Not applicable.

\section{Financial support and sponsorship}

None.

\section{Conflict of interest}

All authors declared that there are no conflicts of interest.

\section{Ethical approval and consent to participate}

Not applicable.

\section{Consent for publication}

Not applicable.

\section{Copyright}

(c) The Author(s) 2022.

\section{REFERENCES}

1. Garcia M, Mulvagh SL, Merz CN, Buring JE, Manson JE. Cardiovascular disease in women: clinical perspectives. Circ Res 2016;118:1273-93. DOI PubMed PMC

2. Calabrò P, Niccoli G, Gragnano F, et al; Working Group of Interventional Cardiology of the Italian Society of Cardiology. Are we ready for a gender-specific approach in interventional cardiology? Int J Cardiol 2019;286:226-33. DOI PubMed

3. Iung B, Delgado V, Rosenhek R, et al; EORP VHD II Investigators. Contemporary presentation and management of valvular heart disease: the EURObservational Research Programme Valvular Heart Disease II Survey. Circulation 2019;140:1156-69. DOI PubMed

4. Baumgartner H, Falk V, Bax JJ, et al; ESC Scientific Document Group. 2017 ESC/EACTS Guidelines for the management of valvular heart disease. Eur Heart J 2017;38:2739-91. DOI PubMed

5. Virani SS, Alonso A, Benjamin EJ, et al; American Heart Association Council on Epidemiology and Prevention Statistics Committee and Stroke Statistics Subcommittee. Heart disease and stroke statistics-2020 update: a report from the American Heart Association. Circulation 2020;141:e139-596. DOI PubMed

6. Shames S, Gillam LD. Sex differences in aortic valve calcification. Circ Cardiovasc Imaging 2013;6:8-10. DOI PubMed

7. Summerhill VI, Moschetta D, Orekhov AN, Poggio P, Myasoedova VA. Sex-specific features of calcific aorticvalve disease. Int J Mol Sci 2020;21:5620. DOI

8. Chandrasekhar J, Dangas G, Mehran R. Valvular heart disease in women, differential remodeling, and response to new therapies. Curr Treat Options Cardiovasc Med 2017;19:74. DOI PubMed

9. Cramariuc D, Rogge BP, Lønnebakken MT, et al. Sex differences in cardiovascular outcome during progression of aortic valve stenosis. Heart 2015;101:209-14. DOI PubMed PMC 
10. Nguyen V, Mathieu T, Melissopoulou M, et al. Sex differences in the progression of aortic stenosis and prognostic implication: the COFRASA-GENERAC Study. JACC Cardiovasc Imaging 2016;9:499-501. DOI PubMed

11. McNeely C, Vassileva C. Mitral valve surgery in women: another target for eradicating sex inequality. Circ Cardiovasc Qual Outcomes 2016;9:S94-6. DOI PubMed

12. Tribouilloy C, Bohbot Y, Rusinaru D, et al. Excess mortality and undertreatment of women with severe aortic stenosis. J Am Heart Assoc 2021;10:e18816. DOI PubMed PMC

13. Généreux P, Stone GW, O'Gara PT, et al. Natural history, diagnostic approaches, and therapeutic strategies for patients with asymptomatic severe aortic stenosis. J Am Coll Cardiol 2016;67:2263-88. DOI PubMed

14. Steeds RP, Messika-Zeitoun D, Thambyrajah J, et al; IMPULSE registry group. IMPULSE: the impact of gender on the presentation and management of aortic stenosis across Europe. Open Heart 2021;8:e01443. DOI PubMed PMC

15. Singh A, Chan DCS, Greenwood JP, et al. Symptom onset in aortic stenosis: relation to sex differences in left ventricular remodeling. JACC Cardiovasc Imaging 2019;12:96-105. DOI PubMed

16. Dobson LE, Musa TA, Uddin A, et al. Gender influences left ventricular remodelling in the setting of aortic stenosis but does not appear to impact on reverse remodelling following transcatheter aortic valve implantation. J Cardiovasc Magn Reson 2015;17:P332. DOI

17. Bech-hanssen O, Wallentin I, Houltz E, Beckman Suurküla M, Larsson S, Caidahl K. Gender differences in patients with severe aortic stenosis: impact on preoperative left ventricular geometry and function, as well as early postoperative morbidity and mortality. Eur $J$ Cardiothorac Surg 1999;15:24-30. DOI PubMed

18. Chin CW, Khaw HJ, Luo E, et al. Echocardiography underestimates stroke volume and aortic valve area: implications for patients with small-area low-gradient aortic stenosis. Can J Cardiol 2014;30:1064-72. DOI PubMed PMC

19. Michelena HI, Margaryan E, Miller FA, et al. Inconsistent echocardiographic grading of aortic stenosis: is the left ventricular outflow tract important? Heart 2013;99:921-31. DOI PubMed

20. Pibarot P, Dumesnil JG. Low-flow, low-gradient aortic stenosis with normal and depressed left ventricular ejection fraction. $J$ Am Coll Cardiol 2012;60:1845-53. DOI PubMed

21. Tastet L, Kwiecinski J, Pibarot P, et al. Sex-related differences in the extent of myocardial fibrosis in patients with aortic valve stenosis. JACC Cardiovasc Imaging 2020;13:699-711. DOI PubMed

22. Boulif J, Gerber B, Slimani A, et al. Assessment of aortic valve calcium load by multidetector computed tomography. Anatomical validation, impact of scanner settings and incremental diagnostic value. J Cardiovasc Comput Tomogr 2017;11:360-6. DOI PubMed

23. Nguyen V, Cimadevilla C, Estellat C, et al. Haemodynamic and anatomic progression of aortic stenosis. Heart 2015;101:943-7. DOI PubMed

24. Tuncay V, Prakken N, van Ooijen PM, Budde RP, Leiner T, Oudkerk M. Semiautomatic, quantitative measurement of aortic valve area using CTA: validation and comparison with transthoracic echocardiography. Biomed Res Int 2015;2015:648283. DOI PubMed PMC

25. Kamperidis V, van Rosendael PJ, Katsanos S, et al. Low gradient severe aortic stenosis with preserved ejection fraction: reclassification of severity by fusion of Doppler and computed tomographic data. Eur Heart J 2015;36:2087-96. DOI PubMed

26. Clavel MA, Pibarot P, Messika-Zeitoun D, et al. Impact of aortic valve calcification, as measured by MDCT, on survival in patients with aortic stenosis: results of an international registry study. J Am Coll Cardiol 2014;64:1202-13. DOI PubMed PMC

27. Nchimi A, Dibato JE, Davin L, Schoysman L, Oury C, Lancellotti P. Predicting disease progression and mortality in aortic stenosis: a systematic review of imaging biomarkers and meta-analysis. Front Cardiovasc Med 2018;5:112. DOI PubMed PMC

28. Pradelli D, Faden G, Mureddu G, et al. Impact of aortic or mitral valve sclerosis and calcification on cardiovascular events and mortality: a meta-analysis. Int J Cardiol 2013;170:e51-5. DOI PubMed

29. Di Minno MND, Poggio P, Conte E, et al. Cardiovascular morbidity and mortality in patients with aortic valve calcification: a systematic review and meta-analysis. J Cardiovasc Comput Tomogr 2019;13:190-5. DOI PubMed

30. Myasoedova VA, Di Minno A, Songia P, et al. Sex-specific differences in age-related aortic valve calcium load: a systematic review and meta-analysis. Ageing Res Rev 2020;61:101077. DOI PubMed

31. Cueff C, Serfaty JM, Cimadevilla C, et al. Measurement of aortic valve calcification using multislice computed tomography: correlation with haemodynamic severity of aortic stenosis and clinical implication for patients with low ejection fraction. Heart 2011;97:721-6. DOI PubMed

32. Clavel MA, Messika-Zeitoun D, Pibarot P, et al. The complex nature of discordant severe calcified aortic valve disease grading: new insights from combined Doppler echocardiographic and computed tomographic study. J Am Coll Cardiol 2013;62:2329-38. DOI PubMed

33. Voisine M, Hervault M, Shen M, et al. Age, sex, and valve phenotype differences in fibro-calcific remodeling of calcified aortic valve. J Am Heart Assoc 2020;9:e015610. DOI PubMed PMC

34. Kvidal P, Bergström P, Hörte L, Ståhle E. Observed and relative survival after aortic valve replacement. J Am Coll Cardiol 2000;35:747-56. DOI PubMed

35. Otto CM, Nishimura RA, Bonow RO, et al; Writing Committee Members. 2020 ACC/AHA Guideline for the management of patients with valvular heart disease: executive summary: a report of the American College of Cardiology/American Heart Association Joint Committee on Clinical Practice Guidelines. J Am Coll Cardiol 2021;77:450-500. DOI PubMed

36. Singh A, Musa TA, Treibel TA, et al. Sex differences in left ventricular remodelling, myocardial fibrosis and mortality after aortic valve replacement. Heart 2019;105:1818-24. DOI PubMed PMC

37. Shan Y, Pellikka PA. Aortic stenosis in women. Heart 2020;106:970-6. DOI PubMed 
38. Pighi M, Piazza N, Martucci G, et al. Sex-specific determinants of outcomes after transcatheter aortic valve replacement. Circ Cardiovasc Qual Outcomes 2019;12:e05363. DOI PubMed

39. O'Connor SA, Morice MC, Gilard M, et al. Revisiting sex equality with transcatheter aortic valve replacement outcomes: a collaborative, patient-level meta-analysis of 11,310 patients. J Am Coll Cardiol 2015;66:221-8. DOI PubMed

40. Kataruka A, Otto CM. Valve durability after transcatheter aortic valve implantation. J Thorac Dis 2018;10:S3629-36. DOI PubMed PMC

41. Onorati F, D'Errigo P, Barbanti M, et al; OBSERVANT Research Group. Different impact of sex on baseline characteristics and major periprocedural outcomes of transcatheter and surgical aortic valve interventions: results of the multicenter Italian OBSERVANT Registry. J Thorac Cardiovasc Surg 2014;147:1529-39. DOI PubMed

42. Chaker Z, Badhwar V, Alqahtani F, et al. Sex differences in the utilization and outcomes of surgical aortic valve replacement for severe aortic stenosis. J Am Heart Assoc 2017;6:e006370. DOI PubMed PMC

43. Fuchs C, Mascherbauer J, Rosenhek R, et al. Gender differences in clinical presentation and surgical outcome of aortic stenosis. Heart 2010;96:539-45. DOI PubMed

44. Milavetz DL, Hayes SN, Weston SA, Seward JB, Mullany CJ, Roger VL. Sex differences in left ventricular geometry in aortic stenosis: impact on outcome. Chest 2000;117:1094-9. DOI PubMed

45. Rahimtoola SH. Valvular heart disease/cardiac surgery. J Am Coll Cardiol 2006;47:D37-40. DOI PubMed

46. Tarantini G, Baumgartner H, Frank D, et al. Four-year mortality in women and men after transfemoral transcatheter aortic valve implantation using the SAPIEN 3. Catheter Cardiovasc Interv 2021;97:876-84. DOI PubMed

47. Chieffo A, Petronio AS, Mehilli J, et al; WIN-TAVI Investigators. Acute and 30-day outcomes in women after TAVR: results from the WIN-TAVI (Women's INternational Transcatheter Aortic Valve Implantation) real-world registry. JACC Cardiovasc Interv 2016;9:1589-600. DOI PubMed

48. Chieffo A, Petronio AS, Mehilli J, et al; WIN-TAVI Investigators. 1-year clinical outcomes in women after transcatheter aortic valve replacement: results from the first WIN-TAVI registry. JACC Cardiovasc Interv 2018;11:1-12. DOI PubMed

49. Saad M, Nairooz R, Pothineni NVK, et al. Long-term outcomes with transcatheter aortic valve replacement in women compared with men: evidence from a meta-analysis. JACC Cardiovasc Interv 2018;11:24-35. DOI PubMed

50. Szerlip M, Gualano S, Holper E, et al. Sex-specific outcomes of transcatheter aortic valve replacement with the SAPIEN 3 valve: insights from the PARTNER II S3 high-risk and intermediate-risk cohorts. JACC Cardiovasc Interv 2018;11:13-20. DOI PubMed

51. Wang TY, Gracia E, Callahan S, et al. Gender disparities in management and outcomes following transcatheter aortic valve implantation with newer generation transcatheter valves. Am J Cardiol 2019;123:1489-93. DOI PubMed

52. Leon MB, Smith CR, Mack MJ, et al; PARTNER 2 Investigators. Transcatheter or surgical aortic-valve replacement in intermediaterisk patients. N Engl J Med 2016;374:1609-20. DOI PubMed

53. Ruge H, Burri M, Erlebach M, Lange R. Access site related vascular complications with third generation transcatheter heart valve systems. Catheter Cardiovasc Interv 2021;97:325-32. DOI PubMed

54. Toggweiler S, Gurvitch R, Leipsic J, et al. Percutaneous aortic valve replacement: vascular outcomes with a fully percutaneous procedure. J Am Coll Cardiol 2012;59:113-8. DOI PubMed

55. Di Mario C, Goodwin M, Ristalli F, et al. A prospective registry of intravascular lithotripsy-enabled vascular access for transfemoral transcatheter aortic valve replacement. JACC Cardiovasc Interv 2019;12:502-4. DOI PubMed

56. Dencker D, Taudorf M, Luk NH, et al. Frequency and effect of access-related vascular injury and subsequent vascular intervention after transcatheter aortic valve replacement. Am J Cardiol 2016;118:1244-50. DOI PubMed

57. Witberg G, Tzalamouras V, Adams H, et al. Routine ultrasound or fluoroscopy use and risk of vascular/bleeding complications after transfemoral TAVR. JACC Cardiovasc Interv 2020;13:1460-8. DOI PubMed

58. Power D, Schäfer U, Guedeney P, et al. Impact of percutaneous closure device type on vascular and bleeding complications after TAVR: a post hoc analysis from the BRAVO-3 randomized trial. Catheter Cardiovasc Interv 2019;93:1374-81. DOI PubMed

59. Buchanan GL, Chieffo A, Montorfano M, et al. A "modified crossover technique" for vascular access management in high-risk patients undergoing transfemoral transcatheter aortic valve implantation. Catheter Cardiovasc Interv 2013;81:579-83. DOI PubMed

60. Claessen BE, Tang GHL, Kini AS, Sharma SK. Considerations for optimal device selection in transcatheter aortic valve replacement: a review. JAMA Cardiol 2021;6:102-12. DOI PubMed

61. Lee M, Modine T, Piazza N, Mylotte D. TAVI device selection: time for a patient-specific approach. EuroIntervention 2016;12:Y3741. DOI PubMed

62. Fischer Q, Urena M, Bouleti C, et al. Performing optimal transcatheter aortic valve implantation: the need for tailored use of transcatheter valves. Arch Cardiovasc Dis 2019;112:512-22. DOI PubMed

63. Renker M, Kim WK. Choice of transcatheter heart valve: should we select the device according to each patient's characteristics or should it be "one valve fits all"? Ann Transl Med 2020;8:961. DOI PubMed PMC

64. Faquir N, Ren B, Van Mieghem NM, Bosmans J, de Jaegere PP. Patient-specific computer modelling - its role in the planning of transcatheter aortic valve implantation. Neth Heart J 2017;25:100-5. DOI PubMed PMC

65. Abdelghani M, Mankerious N, Allali A, et al. Bioprosthetic valve performance after transcatheter aortic valve replacement with selfexpanding versus balloon-expandable valves in large versus small aortic valve annuli: insights from the CHOICE trial and the CHOICE-extend registry. JACC Cardiovasc Interv 2018;11:2507-18. DOI PubMed

66. Hase H, Yoshijima N, Yanagisawa R, et al; OCEAN-TAVI Investigators. Transcatheter aortic valve replacement with Evolut R versus Sapien 3 in Japanese patients with a small aortic annulus: the OCEAN-TAVI registry. Catheter Cardiovasc Interv 2021;97:E875-86. DOI PubMed 
67. Lanz J, Kim W, Walther T, et al. Safety and efficacy of a self-expanding versus a balloon-expandable bioprosthesis for transcatheter aortic valve replacement in patients with symptomatic severe aortic stenosis: a randomised non-inferiority trial. Lancet 2019;394:161928. DOI PubMed

68. Mauri V, Kim WK, Abumayyaleh M, et al. Short-term outcome and hemodynamic performance of next-generation self-expanding versus balloon-expandable transcatheter aortic valves in patients with small aortic annulus: a multicenter propensity-matched comparison. Circ Cardiovasc Interv 2017;10:e005013. DOI PubMed

69. Debry N, Sudre A, Amr G, et al. Transcatheter aortic valve implantation for paradoxical low-flow low-gradient aortic stenosis patients. Catheter Cardiovasc Interv 2016;87:797-804. DOI PubMed

70. Ribeiro HB, Webb JG, Makkar RR, et al. Predictive factors, management, and clinical outcomes of coronary obstruction following transcatheter aortic valve implantation: insights from a large multicenter registry. J Am Coll Cardiol 2013;62:1552-62. DOI PubMed

71. Nai Fovino L, Scotti A, Massussi M, et al. Incidence and feasibility of coronary access after transcatheter aortic valve replacement. Catheter Cardiovasc Interv 2020;96:E535-41. DOI PubMed

72. Nai Fovino L, Scotti A, Massussi M, et al. Coronary angiography after transcatheter aortic valve replacement (TAVR) to evaluate the risk of coronary access impairment after TAVR-in-TAVR. J Am Heart Assoc 2020;9:e016446. DOI PubMed PMC

73. Fontana GP, Bedogni F, Groh M, et al. Safety profile of an intra-annular self-expanding transcatheter aortic valve and next-generation low-profile delivery system. JACC Cardiovasc Interv 2020;13:2467-78. DOI PubMed

74. van Gils L, Tchetche D, Latib A, et al. TAVI with current CE-marked devices: strategies for optimal sizing and valve delivery. EuroIntervention 2016;12:Y22-7. DOI PubMed

75. Reardon MJ, Van Mieghem NM, Popma JJ, et al; SURTAVI Investigators. Surgical or transcatheter aortic-valve replacement in intermediate-risk patients. N Engl J Med 2017;376:1321-31. DOI PubMed

76. Mack MJ, Leon MB, Thourani VH, et al; PARTNER 3 Investigators. Transcatheter aortic-valve replacement with a balloonexpandable valve in low-risk patients. N Engl J Med 2019;380:1695-705. DOI PubMed

77. Brouwer J, Nijenhuis VJ, Delewi R, et al. Aspirin with or without clopidogrel after transcatheter aortic-valve implantation. $N$ Engl $J$ Med 2020;383:1447-57. DOI PubMed

78. Nijenhuis VJ, Brouwer J, Delewi R, et al. Anticoagulation with or without clopidogrel after transcatheter aortic-valve implantation. $N$ Engl J Med 2020;382:1696-707. DOI PubMed

79. Dangas GD, Tijssen JGP, Wöhrle J, et al; GALILEO Investigators. A controlled trial of rivaroxaban after transcatheter aortic-valve replacement. N Engl J Med 2020;382:120-9. DOI PubMed

80. Ten Berg J, Sibbing D, Rocca B, et al. Management of antithrombotic therapy in patients undergoing transcatheter aortic valve implantation: a consensus document of the ESC Working Group on Thrombosis and the European Association of Percutaneous Cardiovascular Interventions (EAPCI), in collaboration with the ESC Council on Valvular Heart Disease. Eur Heart J 2021;42:2265-9. DOI PubMed

81. Katz M, Carlos Bacelar Nunes Filho A, Caixeta A, et al; Brazilian TAVI Registry investigators. Gender-related differences on shortand long-term outcomes of patients undergoing transcatheter aortic valve implantation. Catheter Cardiovasc Interv 2017;89:429-36. DOI PubMed

82. Romano S, Buccheri S, Mehran R, Angiolillo DJ, Capodanno D. Gender differences on benefits and risks associated with oral antithrombotic medications for coronary artery disease. Expert Opin Drug Saf 2018;17:1041-52. DOI PubMed

83. Nagao K, Taniguchi T, Morimoto T, et al; CURRENT AS Registry Investigators. Anemia in patients with severe aortic stenosis. Sci Rep 2019;9:1924. DOI PubMed PMC

84. Nicolas J, Claessen BE, Cao D, et al. Preprocedural anemia in females undergoing transcatheter aortic valve implantation: insights from the WIN-TAVI registry. Catheter Cardiovasc Interv 2021;97:E704-15. DOI PubMed

85. Bière L, Launay M, Pinaud F, et al. Influence of sex on mortality and perioperative outcomes in patients undergoing TAVR: insights from the FRANCE 2 registry. J Am Coll Cardiol 2015;65:755-7. DOI PubMed

86. Kodali S, Williams MR, Doshi D, et al. Sex-specific differences at presentation and outcomes among patients undergoing transcatheter aortic valve replacement: a cohort study. Ann Intern Med 2016;164:377-84. DOI PubMed

87. Sannino A, Szerlip M, Harrington K, Schiattarella GG, Grayburn PA. Comparison of baseline characteristics and outcomes in men versus women with aortic stenosis undergoing transcatheter aortic valve implantation. Am J Cardiol 2018;121:844-9. DOI PubMed

88. Doshi R, Shlofmitz E, Meraj P. Comparison of outcomes and complications of transcatheter aortic valve implantation in women versus men (from the national inpatient sample). Am J Cardiol 2018;121:73-7. DOI PubMed

89. Stehli J, Dagan M, Zaman S, et al. Impact of gender on transcatheter aortic valve implantation outcomes. Am J Cardiol 2020;133:98104. DOI PubMed

90. Chandrasekhar J, Dangas G, Yu J, et al; STS/ACC TVT Registry. Sex-based differences in outcomes with transcatheter aortic valve therapy: TVT registry from 2011 to 2014. J Am Coll Cardiol 2016;68:2733-44. DOI PubMed

91. Forrest JK, Adams DH, Popma JJ, et al. Transcatheter aortic valve replacement in women versus men (from the US CoreValve Trials). Am J Cardiol 2016;118:396-402. DOI PubMed

92. D'Ascenzo F, Gonella A, Moretti C, et al. Gender differences in patients undergoing TAVI: a multicentre study. EuroIntervention 2013;9:367-72. DOI PubMed

93. Buja P, Napodano M, Tamburino C, et al; Italian Multicenter CoreValve Registry Investigators. Comparison of variables in men versus women undergoing transcatheter aortic valve implantation for severe aortic stenosis (from Italian Multicenter CoreValve registry). Am J Cardiol 2013;111:88-93. DOI PubMed

94. Humphries KH, Toggweiler S, Rodés-Cabau J, et al. Sex differences in mortality after transcatheter aortic valve replacement for severe 
aortic stenosis. J Am Coll Cardiol 2012;60:882-6. DOI PubMed

95. Czarnecki A, Qiu F, Koh M, et al. Clinical outcomes after trans-catheter aortic valve replacement in men and women in Ontario, Canada. Catheter Cardiovasc Interv 2017;90:486-94. DOI PubMed 